\title{
Solute transport characteristics of a deep soil profile in the Loess Plateau, China
}

\author{
WANG Jiao $^{1,2}$, SHAO Ming'an ${ }^{1,2,3^{*}}$ \\ ${ }^{1}$ Key Laboratory of Ecosystems Network Observation and Modeling, Institute of Geographical Sciences and Natural Resources \\ Research, Chinese Academy of Sciences, Beijing 100101, China; \\ ${ }^{2}$ University of Chinese Academy of Sciences, Beijing 100049, China; \\ ${ }^{3}$ State Key Laboratory of Soil Erosion and Dryland Farming on the Loess Plateau, Northwest A\&F University, Yangling \\ 712100, China
}

\begin{abstract}
Understanding solute transport behaviors of deep soil profile in the Loess Plateau is helpful for ecological construction and agricultural production improvement. In this study, solute transport processes of a deep soil profile were measured by a conservative tracer experiment using 25 undisturbed soil cores (20 $\mathrm{cm}$ long and $7 \mathrm{~cm}$ diameter for each) continuously sampled from the surface downward to the depth of $500 \mathrm{~cm}$ in the Loess Plateau of China. The solute transport breakthrough curves (BTCs) were analyzed in terms of the convection-dispersion equation (CDE) and the mobile-immobile model (MIM). Average pore-water velocity and dispersion coefficient (or effective dispersion coefficient) were calculated using the CDE and MIM. Basic soil properties and water infiltration parameters were also determined to explore their influence on the solute transport parameters. Both pore-water velocity and dispersion coefficient (or effective dispersion coefficient) generally decreased with increasing depth, and the dispersivity fluctuated along the soil profile. There was a good linear correlation between log-transformed pore-water velocity and dispersion coefficient, with a slope of about 1.0 and an average dispersivity of 0.25 for the entire soil profile. Generally speaking, the soil was more homogeneous along the soil profile. Our results also show that hydrodynamic dispersion is the dominant mechanism of solute transport of loess soils in the study area.
\end{abstract}

Keywords: solute transport; loess soil; pore-water velocity; dispersion coefficient; hydraulic conductivity; Loess Plateau

Citation: WANG Jiao, SHAO Ming'an. 2018. Solute transport characteristics of a deep soil profile in the Loess Plateau, China. Journal of Arid Land, 10(4): 628-637. https://doi.org/10.1007/s40333-018-0060-8

\section{Introduction}

Solute transport is an important mode of nutrient flow to plant roots and agro-chemicals to groundwater (Shao et al., 1998; van der Zee and Leijnse, 2013). Understanding the behavior of soil water and soluble substances is critical for increasing nutrient use efficiency and protecting shallow groundwater systems. However, field-scale soil solute transport is complicated and affected by hydraulic properties and heterogeneity of the soil (Huang et al., 1995; Seuntjens et al., 2002; Mallants, 2014). Thus, both theoretical and experimental models have been developed for investigating the behavior of solute transport in soils (e.g., Tsuboyama et al., 1994; Seuntjens et al., 2002; Gao et al., 2010; Koestel et al., 2013; Venkatraman et al., 2014). Theoretically-driven

\footnotetext{
*Corresponding author: SHAO Ming'an (E-mail: shaoma@igsnrr.ac.cn)

Received 2017-11-29; revised 2018-04-12; accepted 2018-04-18

(C) Xinjiang Institute of Ecology and Geography, Chinese Academy of Sciences, Science Press and Springer-Verlag GmbH Germany, part of Springer Nature 2018
} 
mathematical models such as the convection-dispersion equation (CDE) can be used to simulate nonreactive solute transport through saturated porous media under laboratory and field conditions (Lapidus and Amundson, 1952; Nielsen and Biggar, 1962). Also the mobile-immobile model (MIM) can be utilized to describe anomalous transport in heterogeneous porous media (van Genuchten and Wierenga, 1976).

Theoretical models are widely used to conduct experiments on various elements of solute transport in soils (Lennartz, 1999; Zhou et al., 2011; Chotpantarat et al., 2012). However, the well-controlled boundary conditions required for theoretical models are difficult to establish at the field scale. Undisturbed soil columns with well-preserved natural layers can provide useful information on the behavior of solute transport at local scales (Seyfried and Rao, 1987; Mallants, 2014). The depth of most undisturbed soil columns is within few to tenths of centimeters, but the depth of some large columns can reach up to $\geq 100 \mathrm{~cm}$ (Vanclooster et al., 1995; Garré et al., 2010).

The Loess Plateau of China has the largest deposit of loess soil (both in area and depth) and also has the most severe soil and water loss, resulting in ecosystem degradation (Shi and Shao, 2000). Thus, efforts have been made to investigate the spatial distribution of soil water and nutrient at different scales to restore and reconstruct the degraded ecosystem (Fu et al., 2000; Gao et al., 2015; Li et al., 2015). Researches on the processes of solute transport in soils of the Loess Plateau has focused mostly on repacked (Zhou et al., 2011) and undisturbed (Jiang et al., 2012; Yang et al., 2013) soil columns sampled from the surface downward to the depth of less than 100 $\mathrm{cm}$. Little has been done on solute transport behavior in deep soil profiles. Some studies focused on hydrological properties of deep soil layers indicated that soil hydrological properties varied little at the depth of $>500 \mathrm{~cm}$ (Wang et al., 2013; Li et al., 2016). As solute transport depends largely on water movement, evaluating the solute transport processes of soil profile at the depth of 0-500 cm could have significant implications for the management of soil nutrient and groundwater quality.

In this study, we conducted a solute transport experiment in undisturbed soil cores collected in vertical successions from a deep soil profile of the Loess Plateau, and characterized the effects of soil properties and water infiltration parameters on solute transport processes. The parameters for the infiltration of water and solute transport breakthrough curves (BTCs) were determined under steady-state flow conditions. The BTCs were fitted using both the CDE and the MIM. Some basic soil properties were used to explain the variations in solute transport processes of the soil profile.

\section{Materials and methods}

\subsection{Undisturbed soil core sampling}

The undisturbed soil cores were collected in a corn field at Yangling $\left(34^{\circ} 30^{\prime} \mathrm{N}, 108^{\circ} 07^{\prime} \mathrm{E}\right)$ situated in the Loess Plateau, China. The annual mean temperature at the study site is $12.8^{\circ} \mathrm{C}$ and the mean annual precipitation is $530 \mathrm{~mm}$. The soil in the field is Lou soil (Eum-orthic Anthrosol classified using Chinese Soil Taxonomy; Wang et al., 2006). The undisturbed soil cores were collected from 28 September to 2 October in 2017, when the corn was ripe and ready for harvest. A soil pit (150 cm long, $100 \mathrm{~cm}$ wide and $500 \mathrm{~cm}$ deep) was dug and one of the vertical faces was smoothened with a shovel. The soil core sampling was done using a transparent acrylic cylinder ( $7 \mathrm{~cm}$ in internal diameter and $24 \mathrm{~cm}$ in height). The thickness of the cylinder wall was $5 \mathrm{~mm}$ with a sharp bottom end for cutting through soil profile. The cylinder was gently driven into the soil at $3-\mathrm{cm}$ depth each time using a rubber hammer and then removed. The soil outside the cylinder was scrapped off. This process was repeated until the soil core was about $20 \mathrm{~cm}$ into the soil, and the depth was determined by sticking a tape on the wall of the cylinder. The soil core was cut off and covered in a piece of filter paper, a perforated plate and a lid with a drainage hole at the bottom end. The top end was plugged with soil in a plastic bag to prevent the sample from falling off. A total of 25 undisturbed soil cores $(20 \mathrm{~cm}$ long and $7 \mathrm{~cm}$ diameter) were collected in this way from the surface down to the depth of the smoothened face (i.e., 0-500 cm). Then, the soil cores were transported to the laboratory. 


\subsection{Water infiltration and solute transport experiment}

In the laboratory, the soil cores were placed on custom-made shelves. The surface of each soil core was covered with a piece of filter paper to prevent the formation of crust during watering. Small sampling bottles were put under the soil cores to collect drainage water. Deionized water was applied to the top of the cores using Mariotte bottles to maintain a constant water head, which was recorded for each case for the latter calculation. The water table in the Mariotte bottle was measured to calculate the infiltration rate with short-time intervals for the early period and long-time intervals for the later period. The infiltration experiment was terminated when the wetting front reached the bottom of the core. Then the ponding water at soil surface was removed and $0.2 \mathrm{~mol} / \mathrm{L} \mathrm{NaCl}$ solution was used as tracer to seamlessly replace the deionized water. Subsequently, the effluent was collected continuously in a $25 \mathrm{~mL}$ graduated cylinder at fixed intervals and titrated with $0.1 \mathrm{~mol} / \mathrm{L} \mathrm{AgNO}$ solution to determine $\mathrm{Cl}^{-}$concentration until it was close to $0.2 \mathrm{~mol} / \mathrm{L}$.

\subsection{Soil property determination}

In order to measure the basic physical properties, we collected another 50 undisturbed soil samples from the same profile at $10 \mathrm{~cm}$ intervals close to the soil core using a cutting ring with 5 $\mathrm{cm}$ diameter. The saturated hydraulic conductivity $\left(K_{\mathrm{s}}\right)$ was determined using the constant-head method. Soil samples were oven-dried at $105^{\circ} \mathrm{C}$ for $48 \mathrm{~h}$ after $K_{\mathrm{s}}$ measurement to calculate soil water content and bulk density. The disturbed soil samples were also collected at the same depth interval (i.e., $10 \mathrm{~cm}$ interval) for the determination of particle size distribution by laser diffraction method.

\subsection{Model description}

The CDE and MIM were used to simulate the solute transport processes. The one-dimensional equilibrium $\mathrm{CDE}$ is given as Equation 1 (Lapidus and Amundson, 1952):

$$
R \frac{\partial C}{\partial t}=D \frac{\partial^{2} C}{\partial x^{2}}-v \frac{\partial C}{\partial x}
$$

where $R$ is the retardation factor; $C$ is the resident concentration $\left(\mathrm{g} / \mathrm{cm}^{3}\right) ; t$ is the time period $(\min )$; $D$ is the dispersion coefficient $\left(\mathrm{cm}^{2} / \mathrm{min}\right) ; v$ is the pore-water velocity $(\mathrm{cm} / \mathrm{min})$; and $x$ is the distance $(\mathrm{cm})$. For non-reactive tracers, $R$ is equal to 1.0. The MIM for non-equilibrium transport given by van Genuchten and Wagenet (1989) is expressed as follows (Eqs. 2 and 3):

$$
\begin{aligned}
\theta_{\mathrm{m}} \frac{\partial C_{\mathrm{m}}}{\partial t}+\theta_{\mathrm{im}} \frac{\partial C_{\mathrm{im}}}{\partial t} & =\theta_{\mathrm{m}} D \frac{\partial^{2} C_{\mathrm{m}}}{\partial x^{2}}-v_{\mathrm{m}} \theta_{\mathrm{m}} \frac{\partial C_{\mathrm{m}}}{\partial x}, \\
\theta_{\mathrm{im}} \frac{\partial C_{\mathrm{im}}}{\partial t} & =\alpha\left(C_{\mathrm{m}}-C_{\mathrm{im}}\right),
\end{aligned}
$$

where $\theta$ is the volumetric soil water content $(\%) ; \alpha$ is the first-order mass transfer coefficient $\left(\mathrm{min}^{-1}\right)$; and the subscripts $\mathrm{m}$ and im refer to the mobile and immobile regions, respectively. The measured BTCs were fitted for the CDE and MIM to estimate solute transport parameters using the CXTFIT non-linear fitting procedure (Toride et al., 1995). The effective dispersion coefficient $\left(D_{\text {eff }}\right)$ was derived from Equation 4, and it was introduced in the MIM to compare the solute transport parameters between CDE and MIM (van Genuchten and Dalton, 1986).

$$
D_{\text {eff }}=\frac{\theta_{\mathrm{m}}}{\theta} D_{\mathrm{m}}+\frac{\theta_{\mathrm{im}}^{2} v^{2}}{\alpha \theta},
$$

where the first term of the right part of Equation 4 denotes the hydrodynamic dispersion in the mobile phase, and the second term reflects the source-sink effects of solute transfer into and out of the immobile regions.

\subsection{Data analysis}

The solute transport parameters were estimated using the CXTFIT computer program (Toride et 
al., 1995). The figures were plotted with Sigmaplot 12.5 (Systat Software Inc., UK).

\section{Results and discussion}

\subsection{Soil profile properties}

The soil bulk density along the soil profile was in the range of $0.91-1.35 \mathrm{~g} / \mathrm{cm}^{3}$, with an average of $1.10 \mathrm{~g} / \mathrm{cm}^{3}$ (Fig. 1a). The average soil bulk density in the $0-20 \mathrm{~cm}$ soil layer was $1.29 \mathrm{~g} / \mathrm{cm}^{3}$, similar to the value of undisturbed soil in the Loess Plateau reported by Jiao et al. (2011). Soil compaction initially decreased and then increased from the top to the bottom of the soil profile. Wang et al. (2008) observed bulk density distribution in the $0-100 \mathrm{~cm}$ loess soil profile and found that the 10-20 cm soil layer (the so-called plow pan) had the highest compaction.

The vertical distribution of initial gravimetric water content in the soil profile is plotted in Figure $1 \mathrm{~b}$. The soil moisture decreased with increasing depth for the surface $0-20 \mathrm{~cm}$ soil layer and then increased with increasing depth for the $20-100 \mathrm{~cm}$ soil layer. The soil moisture decreased slowly with increasing soil depth below $100 \mathrm{~cm}$ depth, with no significant differences between individual soil layers except for the 390-400 cm soil layer (which could have been due to error). Generally speaking, the shallow soil layer was low in moisture because of the evaporation (Heathman et al., 2003; Wang et al., 2008). The high soil moisture in the surface soil layer in this study may be due to the reason that soil sampling was done after low precipitation events.

The clay content in soils increased at first and then decreased later (Fig. 1c). The maximum clay content was observed at the $30-40 \mathrm{~cm}$ soil layer. Soils with high clay content usually have a high water retention capacity, suggesting that water content in the surface soil layer was largely influenced by climatic and vegetation conditions in the study area.
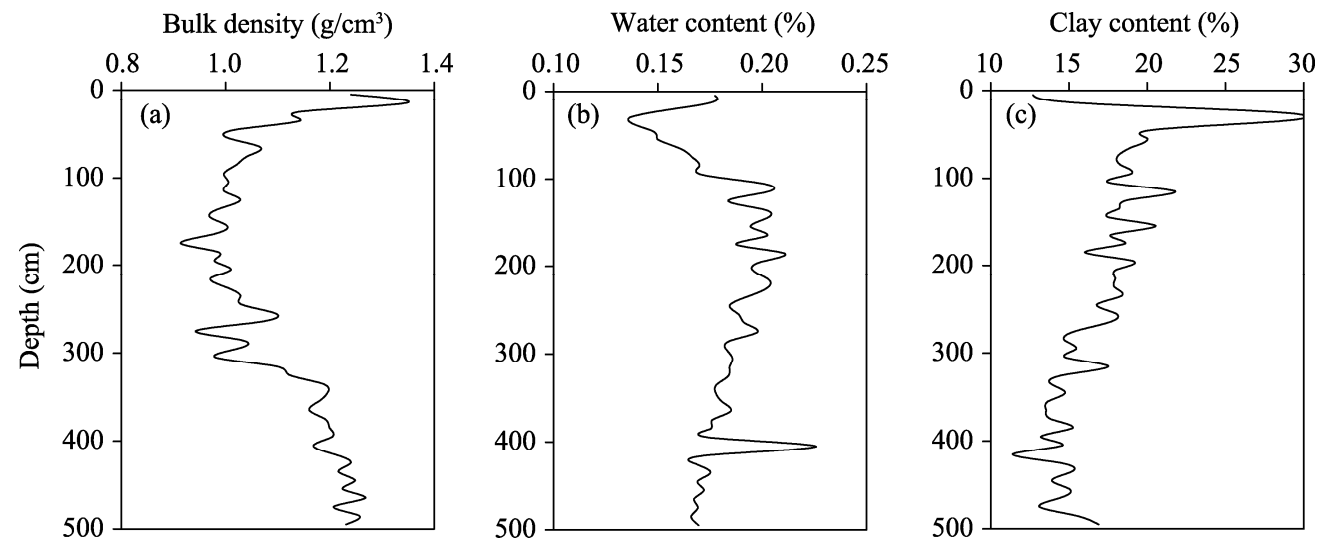

Fig. 1 Vertical distributions of basic soil physical properties along the soil profile

\subsection{Water flow characteristics}

The final infiltration rate of each soil core is shown in Figure 2. No effluent was collected for soil core samples from the $360-380 \mathrm{~cm}$ soil layer after $30 \mathrm{~d}$ of application of water. Therefore, the infiltration rate of this soil layer was assumed to be 0. It is shown in Figure 2 that the soil column above the $200 \mathrm{~cm}$ soil depth had a stronger infiltration capacity than the soil column below the $200 \mathrm{~cm}$ soil depth. Compared with the infiltration rate calculated by Wang et al. (2008), there was a markedly high infiltration rate for the 100-200 cm soil layer in this study. The macro-pores in this soil layer could explain the high infiltration with local peak values of $60-80 \mathrm{~cm}$ soil layer. However, Kang et al. (2002) observed a much greater infiltration rate of $0.16 \mathrm{~cm} / \mathrm{min}$ for the $0-60$ $\mathrm{cm}$ soil layer in a winter wheat field in the southern region of the Loess Plateau, and Zhou et al. (2010) noted an infiltration rate of $0.12 \mathrm{~cm} / \mathrm{min}$ for the $0-10 \mathrm{~cm}$ soil layer in the northern region of the Loess Plateau. The discrepancy may be due to the differences in land use types and vegetation types. 
The vertical variations of $K_{\mathrm{s}}$ along the soil profile shown in Figure 3 indicated that $K_{\mathrm{s}}$ was low both in the 0-200 and 350-500 cm soil layers. The relatively high $K_{\mathrm{s}}$ values in the $200-350 \mathrm{~cm}$ soil layer and at the $480 \mathrm{~cm}$ soil depth may be due to the large soil pores. The differences between the distributions of final infiltration rate and $K_{\mathrm{s}}$ reflected a high spatial variability of soil water infiltration in the study area.

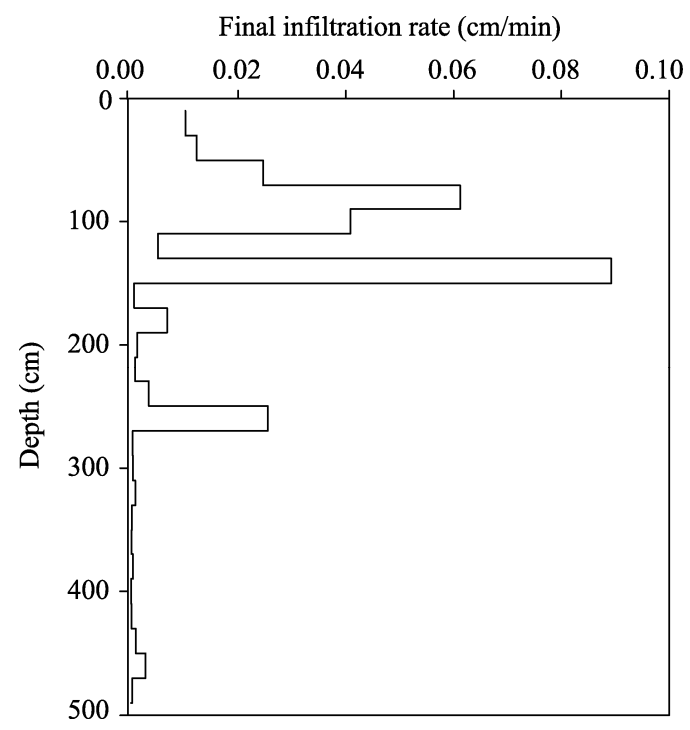

Fig. 2 Vertical distribution of final infiltration rate along the soil profile

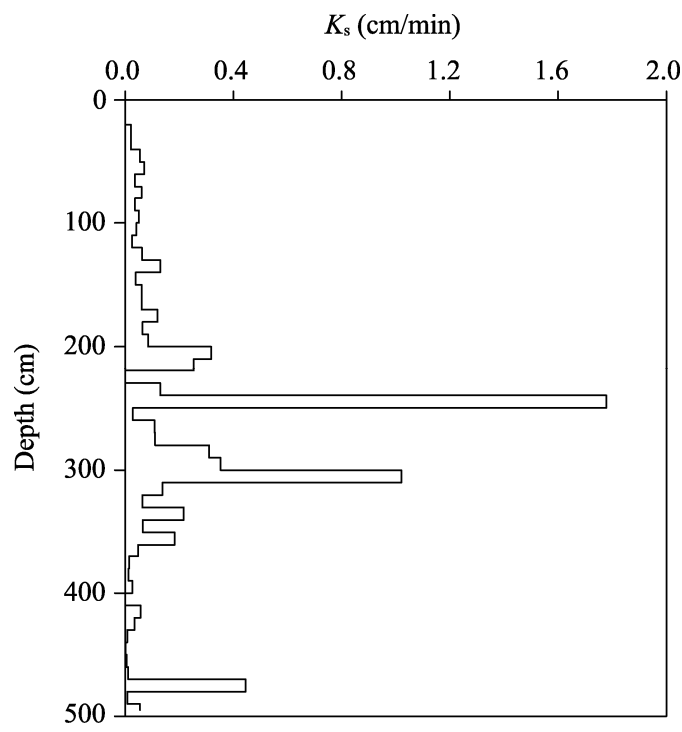

Fig. 3 Vertical distribution of saturated hydraulic conductivity $\left(K_{\mathrm{s}}\right)$ along the soil profile

\subsection{Solute transport processes}

The coefficients of determination $\left(R^{2}\right)$ for curve fitting the BTCs using both CDE and MIM were greater than 0.9 , indicating that the fitting results were reliable. Average pore-water velocity is independently estimated and plotted in Figure 4a, showing a decreasing trend with increasing soil depth in general. The average pore-water velocity was higher in the sampled soil cores at the depth of $0-200 \mathrm{~cm}$ than at the depth of $200-500 \mathrm{~cm}$. The result was in a good agreement with the distribution of final infiltration rate. The pore-water velocity varied dramatically at the $0-200 \mathrm{~cm}$ soil depth, but it was distributed uniformly at the 200-500 soil depth, except for the last $20 \mathrm{~cm}$ 
soil depth. As reported by Mallants et al. (1994), soils near the surface are more heterogeneous.

The mobile-phase velocity $\left(v_{\mathrm{m}}\right)$ was obtained using the MIM $\left(v_{\mathrm{m}}=v /\left(\theta_{\mathrm{m}} / \theta\right)\right.$, where $v_{\mathrm{m}}$ is the mobile-phase velocity $(\mathrm{cm} / \mathrm{min}), v$ is the average pore-water velocity $(\mathrm{cm} / \mathrm{min}), \theta$ is the volumetric soil water content (\%) and the subscript $\mathrm{m}$ refers to the mobile region). The distribution of mobile-phase velocity along the soil profile is plotted in Figure $4 \mathrm{~b}$. The high values at the 100,200, 420 and $460 \mathrm{~cm}$ soil depths could be due to the very low mobile water fraction, where nearly all the water was immobile. Without taking this into consideration, the mobile-phase velocity was less variable than the pore-water velocity. Generally, the mobile-phase velocity decreased with increasing soil depth and became almost constant starting from the $220 \mathrm{~cm}$ soil depth downward to the $360 \mathrm{~cm}$ soil depth.
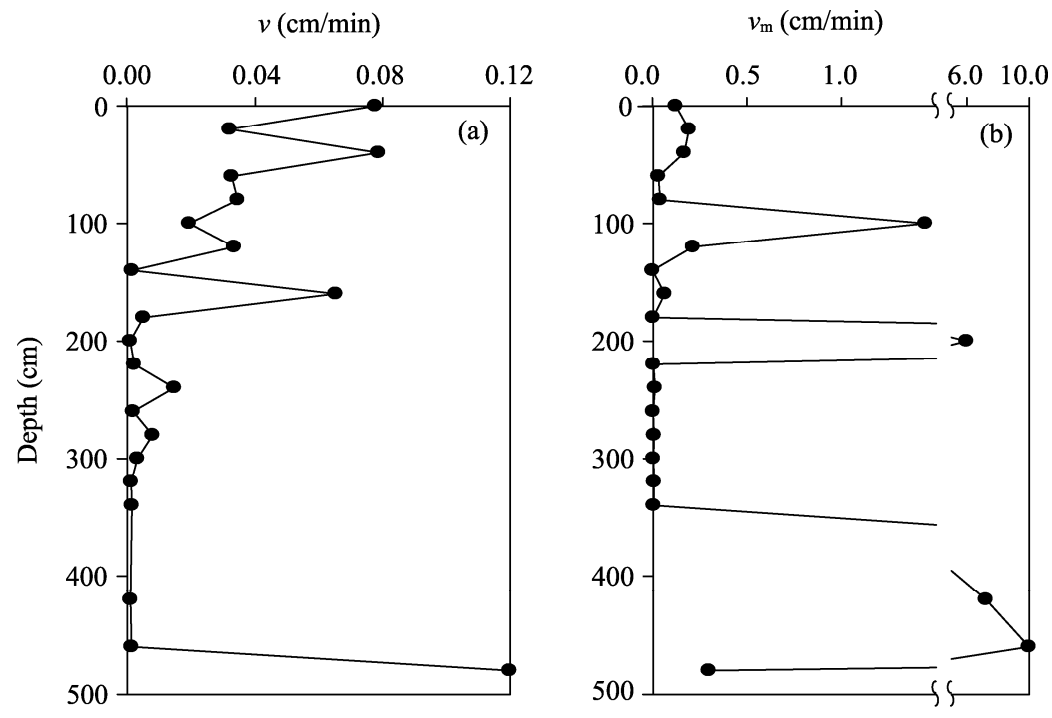

Fig. 4 Vertical distributions of average pore-water velocity $\left(v\right.$, a) and mobile-phase velocity $\left(v_{\mathrm{m}}\right.$, b) along the soil profile

Both of the dispersion coefficient and effective dispersion coefficient were generally larger at the shallow depth than at the deep depth (Fig. 5). The dispersion coefficient varied considerably at the depth of 0-200 cm. However, it became almost constant at the depth of 200-500 cm, except for the deepest soil depths. Soils in the upper region of the soil profile generally had higher porosity values and looser structures, which facilitated solute transport. Soils were more compact at the deep depth, causing high tortuosity of the processes of solute transport. Similarly, the large dispersion coefficient values for soil cores in the $480-500 \mathrm{~cm}$ soil column were due to the presence of macro-pores, which could result in a high water mobility. Generally speaking, the dispersion coefficient is proportional to the pore-water velocity, thus an increase in pore-water velocity always results in an increase in dispersion coefficient. This consistency was also observed in this study, where both pore-water velocity and dispersion coefficient were high at the depth of $0-200 \mathrm{~cm}$.

Comparison of dispersion coefficient pertaining to CDE and MIM (dispersion coefficient and effective dispersion coefficient, respectively) showed that the values derived from the former were in some cases larger than those derived from the latter. This was expected because solute exchange process in MIM was the equivalent of dispersion in CDE (Wang and Shao, 2007; Zhou et al., 2011). Therefore, dispersion coefficient fitted by the MIM accounted for only hydrodynamic dispersion. However, the effective dispersion coefficient values at the 160 and 240 $\mathrm{cm}$ soil depths were larger than the corresponding dispersion coefficient values. This was due to the exchange of solutes between mobile and immobile regions, which could result in relatively far solute travel distances, thus requiring a larger effective dispersion coefficient value to describe it.

Solute transport in structured soils can approach equilibrium CDE when local equilibrium 


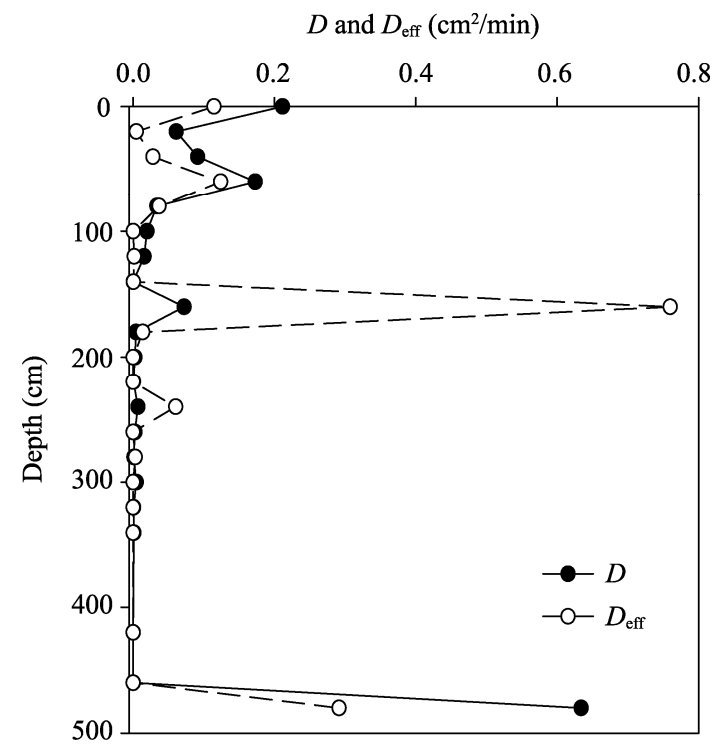

Fig. 5 Vertical distributions of dispersion coefficient $(D)$ and effective dispersion coefficient $\left(D_{\text {eff }}\right)$ along the soil profile

assumptions are met (Parker and Valocchi, 1986). With low pore-water velocity, the mean residence time is larger than the characteristic time for solute exchange between mobile and immobile phases. Therefore, the validity of local equilibrium assumptions is supposed to improve for compact soils. In this study, comparison between dispersion coefficient and effective dispersion coefficient indicated a close agreement for soil cores from 240 to $460 \mathrm{~cm}$ depths. Soil bulk density increased downwards starting from $200 \mathrm{~cm}$ depth (Fig. 1), indicating that deep soils are more compact than shallow soils. For the soil cores at the deep depth $(200-500 \mathrm{~cm})$, solute transport could be described by means of CDE model due to the compaction of soil.

In this study, the estimated values of dispersion coefficient increased with increasing pore-water velocity $\left(R^{2}=0.84, P<0.01\right)$. For each soil core, dispersivity $(\lambda, \mathrm{cm})$ was used to describe the relationship between pore-water velocity and dispersion coefficient $(\lambda=D / v$, where $D$ is the dispersion coefficient $\left(\mathrm{cm}^{2} / \mathrm{min}\right)$ and $v$ is the pore-water velocity $\left.(\mathrm{cm} / \mathrm{min})\right)$. The calculated value of dispersivity fluctuated along the soil profile, with a range of $0.16-5.31 \mathrm{~cm}$ and an average of $1.61 \mathrm{~cm}$. Dispersivity is generally regarded to be characteristic of the entire medium (Bear, 1972). It has typical values of $0.1-2.0 \mathrm{~cm}$ for repacked homogeneous soil columns, which are one or several times higher than those for heterogeneous soil columns (Huang et al., 1995).

Values of pore-water velocity and dispersion coefficient for all soil cores were combined to evaluate the relationship between the two parameters for the whole soil profile. A linear regression equation (Eq. 5) was used to estimate the dispersivity $(\lambda)$ and exponent $(n)$.

$$
D=\lambda v^{n} \text {, }
$$

where $n$ is an empirical parameter, usually in the range of 1-2 (Saffman, 1959; Beven et al., 1993). Log-transformed pore-water velocity and log-transformed dispersion coefficient plotted in Figure 6 showed a good linear correlation. The values of dispersivity and exponent were determined from the regression correlation between log-transformed pore-water velocity and log-transformed dispersion coefficient. By the combination of all the soil cores, ensemble mean values of dispersivity and exponent were obtained, with the values of $2.25 \mathrm{~cm}$ and 1.1561 , respectively. Such a small dispersivity value for undisturbed soil column was also compiled by Jury (1985) and observed by Mallants (2014). The small dispersivity value probably reflected the relative homogeneous nature of loess soil profile, especially at deeper soil layers. The value of exponent was close to 1.0, indicating that hydrodynamic dispersion is the main solute transport process in the study area. A similar exponent value $(n=1.2)$ was observed by Jaynes et al. (1988) in a bromide leachate experiment under continuous flood conditions. Due to the heterogeneity of the 
soil, the correlation between vertical distributions of solute transport parameters and soil properties was not firmly conclusive. However, the above discussion suggested that the spatial fluctuations in solute transport parameters can be explained qualitatively by specific soil physical properties.

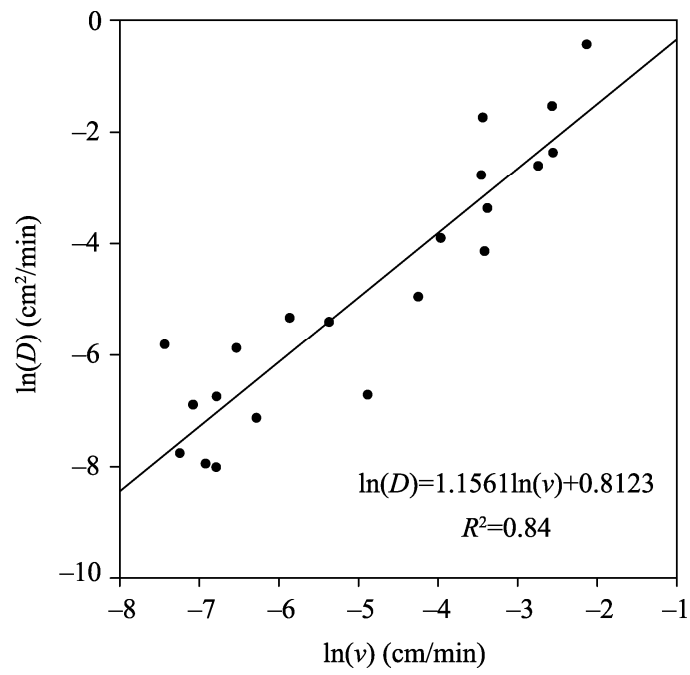

Fig. 6 Correlation between log-transformed pore-water velocity $(\ln (v))$ and $\log$-transformed dispersion coefficient $(\ln (D))$

\section{Conclusions}

A conservative tracer experiment was conducted to characterize the solute transport processes of a deep loess soil profile $(0-500 \mathrm{~cm}$ depth) in the Loess Plateau. Average pore-water velocity was determined independently from the experiment and dispersion coefficients were calculated by fitting the CDE and MIM to the solute concentration vs. time data. The final infiltration rate initially increased and then decreased with increasing soil depth, showing a negative correlation with soil bulk density. The BTCs data for all soil cores can be explained by both CDE and MIM. The measured pore-water velocity had larger values in the shallow soil layers, with fluctuations driven by macro-pores in the soil. Both dispersion coefficient and effective dispersion coefficient generally decreased with increasing soil depth, except for few soil layers. The close agreement between the two parameters (dispersion coefficient and effective dispersion coefficient) below the $200 \mathrm{~cm}$ soil depth indicated that the deep soil layers were largely homogeneous. The dispersivity varied considerably over the entire soil profile and had a magnitude smaller than that for some typical soil cores. The log-transformed pore-water velocity and log-transformed dispersion coefficient exhibited a linear correlation, and the result indicated that the soil was relatively homogeneous. Our results further showed that hydrodynamic dispersion is the main spreading mechanism of solute transport of loess soils in the study area.

\section{Acknowledgements}

This research was supported by the National Natural Science Foundation of China $(41571130081,41530854)$. We thank the editors and reviewers for their useful comments and suggestions on this manuscript.

\section{References}

Bear J. 1972. Dynamics of Fluid in Porous Media. New York: Elsevier, 174-175.

Beven K J, Henderson D E, Reeves A D. 1993. Dispersion parameters for undisturbed partially saturated soil. Journal of Hydrology, 143(1-2): 19-43.

Chotpantarat S, Ong S K, Sutthirat C, et al. 2012. Competitive modeling of sorption and transport of $\mathrm{Pb}^{2+}, \mathrm{Ni}^{2+}, \mathrm{Mn}^{2+}$ and $\mathrm{Zn}^{2+}$ 
under binary and multi-metal systems in lateritic soil columns. Geoderma, 189-190: 278-287.

Fu B J, Chen L D, Ma K M, et al. 2000. The relationships between land use and soil conditions in the hilly area of the loess plateau in northern Shaanxi, China. CATENA, 39(1): 69-78.

Gao G Y, Zhan H B, Feng S Y, et al. 2010. A new mobile-immobile model for reactive solute transport with scale-dependent dispersion. Water Resources Research, 46(8): W08533.

Gao L, Shao M A, Peng X H, et al. 2015. Spatio-temporal variability and temporal stability of water contents distributed within soil profiles at a hillslope scale. CATENA, 132: 29-36.

Garré S, Koestel J, Günther T, et al. 2010. Comparison of heterogeneous transport processes observed with electrical resistivity tomography in two soils. Vadose Zone Journal, 9(2): 336-349.

Heathman G C, Starks P J, Ahuja L R, et al. 2003. Assimilation of surface soil moisture to estimate profile soil water content. Journal of Hydrology, 279(1-4): 1-17.

Huang K, Toride N, Van Genuchten M T. 1995. Experimental investigation of solute transport in large, homogeneous and heterogeneous, saturated soil columns. Transport in Porous Media, 18(3): 283-302.

Jaynes D B, Rice R C, Bowman R S. 1988. Transport of a conservative tracer in the field under continuous flood irrigation. Soil Science Society of America Journal, 52(3): 618-624.

Jiang Y L, Zhou B B, Shao M A, et al. 2012. Simulating the chloride transport in a loess plateau soil with two-region model and two-flow domain model. Journal of Soil and Water Conservation, 26(5): 224-228, 234. (in Chinese)

Jiao F, Wen Z M, An S S. 2011. Changes in soil properties across a chronosequence of vegetation restoration on the Loess Plateau of China. CATENA, 86(2): 110-116.

Jury W A. 1985. Spatial variability of soil physical parameters in solute migration: a critical literature review. In: University of California. EPRI-EA-4228. Riverside, USA.

Kang S Z, Zhang L, Liang Y L, et al. 2002. Effects of limited irrigation on yield and water use efficiency of winter wheat in the Loess Plateau of China. Agricultural Water Management, 55(3): 203-216.

Koestel J K, Norgaard T, Luong N M, et al. 2013. Links between soil properties and steady-state solute transport through cultivated topsoil at the field scale. Water Resources Research, 49(2): 790-807.

Lapidus L, Amundson N R. 1952. Mathematics of adsorption in beds. VI. The effect of longitudinal diffusion in ion exchange and chromatographic columns. The Journal of Physical Chemistry, 56(8): 984-988.

Lennartz B. 1999. Variation of herbicide transport parameters within a single field and its relation to water flux and soil properties. Geoderma, 91(3-4): 327-345.

Li X Z, Shao M A, Jia X X, et al. 2015. Landscape-scale temporal stability of soil water storage within profiles on the semiarid Loess Plateau of China. Journal of Soils and Sediments, 15(4): 949-961.

Li X Z, Shao M A, Jia X X, et al. 2016. Profile distribution of soil-water content and its temporal stability along a 1340-m long transect on the Loess Plateau, China. CATENA, 137: 77-86.

Mallants D, Vanclooster M, Meddahi M, et al. 1994. Estimating solute transport in undisturbed soil columns using time-domain reflectometry. Journal of Contaminant Hydrology, 17(2): 91-109.

Mallants D. 2014. Field-scale solute transport parameters derived from tracer tests in large undisturbed soil columns. Soil Research, 52(1): 13-26.

Nielsen D R, Biggar J W. 1962. Miscible displacement: III. Theoretical considerations. Soil Science Society of America Journal, 26(3): 216-221

Parker J C, Valocchi A J. 1986. Constraints on the validity of equilibrium and first-order kinetic transport models in structured soils. Water Resources Research, 22(3): 399-407.

Saffman P G. 1959. A theory of dispersion in a porous medium. Journal of Fluid Mechanics, 6(3): 321-349.

Seuntjens P, Mallants D, Šimůnek J, et al. 2002. Sensitivity analysis of physical and chemical properties affecting field-scale cadmium transport in a heterogeneous soil profile. Journal of Hydrology, 264(1-4): 185-200.

Seyfried M S, Rao P S C. 1987. Solute transport in undisturbed columns of an aggregated tropical soil: Preferential flow effects. Soil Science Society of America Journal, 51(6): 1434-1444.

Shao M, Horton R, Miller R K. 1998. An approximate solution to the convection-dispersion equation of solute transport in soil. Soil Science, 163(5): 339-345.

Shi H, Shao M A. 2000. Soil and water loss from the Loess Plateau in China. Journal of Arid Environments, 45(1): 9-20.

Toride N, Leij F, Van Genuchten M T. 1995. The CXTFIT code for estimating transport parameters from laboratory or field tracer experiments. In: US Salinity Laboratory. Research Report No. 137. Riverside, California.

Tsuboyama Y, Sidle R C, Noguchi S, et al. 1994. Flow and solute transport through the soil matrix and macropores of a hillslope segment. Water Resources Research, 30(4): 879-890. 
van der Zee S E A T M, Leijnse A. 2013. Solute transport in soil. In: Soriano M C H. Soil Processes and Current Trends in Quality Assessment. Rijeka, Croatia: InTech., 34-86.

van Genuchten M T, Wierenga P J. 1976. Mass transfer studies in sorbing porous media I. Analytical solutions. Soil Science Society of America Journal, 40(4): 473-480.

van Genuchten M T, Dalton F N. 1986. Models for simulating salt movement in aggregated field soils. Geoderma, 38(1-4): $165-183$.

van Genuchten M T, Wagenet R J. 1989. Two-site/two-region models for pesticide transport and degradation: Theoretical development and analytical solutions. Soil Science Society of America Journal, 53(5): 1303-1310.

Vanclooster M, Mallants D, Vanderborght J, et al. 1995. Monitoring solute transport in a multi-layered sandy lysimeter using time domain reflectometry. Soil Science Society of America Journal, 59(2): 337-344.

Venkatraman A, Hesse M A, Lake L W, et al. 2014. Analytical solutions for flow in porous media with multicomponent cation exchange reactions. Water Resources Research, 50(7): 5831-5847.

Wang F, Bian Y R, Jiang X, et al. 2006. Residual characteristics of organochlorine pesticides in Lou soils with different fertilization modes. Pedosphere, 16(2): 161-168.

Wang H F, Shao M A. 2007. Experimental study of non-reactive anion transport in the soil-stone mixture. Advances in Water Science, 18(2): 164-169. (in Chinese)

Wang R, Liu W Z, Li Z. 2008. Physical properties of soils along a $10 \mathrm{~m}$ deep soil profile in loess tableland. Acta Pedologica Sinica, 45(3): 550-554. (in Chinese)

Wang Y Q, Shao M A, Liu Z P. 2013. Vertical distribution and influencing factors of soil water content within 21-m profile on the Chinese Loess Plateau. Geoderma, 193-194: 300-310.

Yang T, Wang Q J, Zhou B B, et al. 2013. Preferential solute transport in a loess silt loam soil. Soil Science, 178(4): 157-164.

Zhou B B, Shao M A, Wang Q J, et al. 2011. Effects of different rock fragment contents and sizes on solute transport in soil columns. Vadose Zone Journal, 10(1): 386-393.

Zhou Z C, Gan Z T, Shangguan Z P, et al. 2010. Effects of grazing on soil physical properties and soil erodibility in semiarid grassland of the Northern Loess Plateau (China). CATENA, 82(2): 87-91. 